\title{
Role of prolactin/adenoma maximum diameter and prolactin/adenoma volume in the differential diagnosis of prolactinomas and other types of pituitary adenomas
}

\author{
YINXING HUANG $^{1^{*}}, \mathrm{CHENYU} \mathrm{DING}^{2 *}$, FANGFANG ZHANG $^{3}$, \\ DEYONG XIAO $^{4}$, LIN ZHAO ${ }^{1}$ and SHOUSEN WANG ${ }^{1}$
}

\begin{abstract}
${ }^{1}$ Department of Neurosurgery, Fuzhou General Hospital, Fujian Medical University; ${ }^{2}$ Department of Neurosurgery, Fuzong Clinical Medical College of Fujian Medical University, Fuzhou, Fujian 350025;

${ }^{3}$ Department of Endocrinology, First Hospital of Fuzhou Affiliated to Fujian Medical University, Fuzhou, Fujian 350009;

${ }^{4}$ Department of Neurosurgery, The First Affiliated Hospital of Xiamen University, Xiamen, Fujian 361003, P.R. China
\end{abstract}

Received October 25, 2016; Accepted September 28, 2017

DOI: $10.3892 / \mathrm{ol} .2017 .7462$

\begin{abstract}
The present study aimed to investigate the function of the prolactin/adenoma maximum diameter (PRL/MD) and the prolactin/adenoma volume (PRL/V) in the differential diagnosis of prolactinomas and other types of pituitary adenomas. A total of 118 patients with pituitary adenoma, hyperprolactinemia and a plasma PRL $<250 \mu \mathrm{g} / 1$ were enrolled. Clinical data from these patients were retrospectively analyzed. A receiver operating characteristic curve was plotted. The function of PRL, PRL/MD and PRL/V in the differential diagnosis of prolactinomas and other types of pituitary adenomas was compared. The results revealed that a PRL of $55.65 \mu \mathrm{g} / \mathrm{l}$ was the most accurate [sensitivity (SE), 0.800; specificity (SP), 0.716; positive predictive value (PPV), 0.857; negative predictive value (NPV), 0.933; and Youden index (YI), 0.516]. The PRL/MD with the highest diagnostic value was $4.03 \mu \mathrm{g} /(1 \mathrm{x} \mathrm{mm})$ (SE, 0.800; SP, 0.898; PPV, 0.727; NVP, 0.929; and YI, 0.698). The PRL/V with the highest diagnostic value was $54.00 \mu \mathrm{g} /\left(1 \mathrm{x} \mathrm{cm}^{3}\right)$ (SE, 0.900; SP, 0.966; PPV, 0.900; NVP, 0.966; and YI, 0.866). The PRL/MD tended to be of higher diagnostic accuracy than PRL, but this difference was not statistically significant $(\mathrm{P}=0.097)$. The differentiation ability of PRL/V was significantly stronger than that of PRL $(\mathrm{P}=0.028)$. Thus, serum PRL, PRL/MD and PRL/V levels may be able to differentiate prolactinomas from other types of hyperprolactinemia-causing pituitary
\end{abstract}

Correspondence to: Dr Shousen Wang, Department of Neurosurgery, Fuzhou General Hospital, Fujian Medical University, 156 North Xierhuan Road, Fuzhou, Fujian 350025, P.R. China E-mail: wangss1965@126.com

${ }^{*}$ Contributed equally

Key words: pituitary adenoma, hyperprolactinemia, prolactin, prolactinomas, differential diagnosis adenomas prior to treatment. PRL/V may be better than the PRL level in achieving a differential diagnosis, and the optimal PRL/V ratio for differentiating prolactinomas from other types of hyperprolactinemia-causing pituitary adenomas was $54.00 \mu \mathrm{g} /\left(1 \mathrm{x} \mathrm{cm}^{3}\right)$.

\section{Introduction}

Hyperprolactinemia is most commonly caused by prolactinoma, but may also be caused by other types of pituitary adenomas, in addition to the pituitary stalk interruption effect, peritumoral pituitary compression and endocrine feedback $(1,2)$. Pituitary adenoma-associated hyperprolactinemia is usually considered to be caused by prolactinoma, but other types of pituitary adenomas may also cause secondary hyperprolactinemia. For example, the incidence of non-functional pituitary large adenoma-associated secondary hyperprolactinemia is $34.8-41.2 \%$ (3-8). The presence of secondary hyperprolactinemia makes it difficult to differentiate prolactinoma from other types of pituitary adenomas (9-12). However, the treatment for prolactinoma differs greatly from that of other types of pituitary adenomas. Thus, it is of great importance to differentiate prolactinoma from other types of pituitary adenomas. Currently, clinical symptoms, imaging and pituitary hormone tests are used for this differential diagnosis, but the diagnostic accuracy of these techniques is limited (11,13-15).

Therefore, the present study was designed to identify a novel diagnostic approach for differentiating prolactinoma from other types of pituitary adenomas. The prolactin (PRL) level in prolactinomas is strongly associated with tumor size (16). As the tumor size increases, the synthesis and release of PRL is enhanced. However, the PRL levels of other types of pituitary adenomas depend more upon the location of the adenomas (17) and the increased size of the adenoma may not lead to a significant increase in PRL.

The present study proposed the use of the prolactin/adenoma maximum diameter (PRL/MD) and the prolactin/adenoma volume (PRL/V) as novel diagnostic tools for prolactinoma, 
and the diagnostic value of these methods was investigated. Due to the fact that mis-differentiation occurs only in large adenomas, the present study primarily included large pituitary adenomas (diameter $\geq 10 \mathrm{~mm}$ ). Meanwhile, the Hyperprolactinemia Treatment Guidelines of the European Endocrine Society demonstrate that a PRL $>250 \mu \mathrm{g} / 1$ is most likely caused by prolactinoma (15). Therefore, only patients with a PRL between the upper limit of the normal range and $250 \mu \mathrm{g} / 1$ were included in the present study.

\section{Patients and methods}

Patients. Data from 516 patients with pituitary adenoma who had been admitted to the Department of Neurosurgery, Fuzhou General Hospital (Fuzhou, China) between December 2008 and December 2014 were retrospectively analyzed. A total of 178 of these were cases of large pituitary adenoma with hyperprolactinemia.

The inclusion criteria of the present study were as follows: i) Pituitary adenoma diagnosed by pathology and classified by immunohistochemistry $(18,19)$; ii) having undergone $\geq 1$ set of concurrent pituitary hormone tests and magnetic resonance imaging (MRI) prior to treatment; iii) a pituitary adenoma diameter $>10 \mathrm{~mm}$; and iv) a PRL between the upper limit of the normal range [PRL, 2.1-17.7 $\mu \mathrm{g} / \mathrm{l}$ (male), 2.8-29.2 $\mu \mathrm{g} / \mathrm{l}$ (female, not pregnant), 1.8-20.3 $\mu \mathrm{g} / 1$ (female, menopause) and 3.4-33.4 $\mu \mathrm{g} / 1$ (female, ovulatory phase)] and $250 \mu \mathrm{g} / 1$. The exclusion criteria were as follows: i) The presence of other primary endocrine diseases, including hyperthyroidism and Cushing's syndrome; ii) pituitary hormone tests exhibiting growth hormone $(\mathrm{GH} ;<10 \mu \mathrm{g} / \mathrm{l})$, thyroid-stimulating hormone (TSH; 0.35-5.5 $\mu \mathrm{IU} / \mathrm{ml}$ ) or adrenocorticotropic hormone (ACTH; 4.7-48.8 pg/ml) levels above the upper normal limit; iii) a history of glucocorticoid replacement therapy; and iv) recent treatment with drugs that affect pituitary hormone levels, including antipsychotic drugs, opioids, proton pump inhibitors, estrogen preparations and calcium antagonists. The surgical indications were as follows: i) A poor efficacy of medical therapy after 3-6 months of treatment; ii) the inability to tolerate medical therapy; iii) a lack of mental capacity to live with the tumor (determined by an interview with the patients or their family) or refusal of long-term medication; iv) the presence of tumor apoplexy, manifesting as severe headaches and a sharp decrease in vision; and v) experienced surgeons anticipating total tumor removal by surgery having fully taken into consideration the wishes of the patients (20).

Finally, there were 118 patients included in the present study. Patients were divided into two groups, with PRL(+), $\mathrm{GH}(-)$, ACTH(-), TSH(-), follicle-stimulating hormone (FSH) $(-)$, and luteinizing hormone $(\mathrm{LH})(-)$ patients (as assessed by immunohistochemistry) in group A (prolactinoma group, $\mathrm{n}=30$ ) and all other patients in group B (other types of pituitary adenoma, $n=88$ ). The mean ages of the two groups were 35.27 (range, 19-64 years) in group A and 47.61 in group B (range, 20-74 years). The male:female ratio consisted of 7:23 in group A and 33:55 in group B. Prior written and informed consent was obtained from each patient and the study was approved by the Ethics Review Board of Fuzhou General Hospital.
Determination of tumor maximum diameter $(M D)$ and tumor volume (V) by enhanced and plain MRI scanning. All patients underwent an enhanced and a plain MRI scan using a Siemens 3.0T MRI machine (Magnetom; Siemens AG, Munich, Germany). The scan sequences included at least axial and sagittal T1-weighted imaging, axial and coronal T2-weighted imaging, coronal fluid-attenuated inversion recovery and a three-dimensional enhanced scan. The imaging was measured at an INFINITT PACS workstation (PACS; INFINITT Healthcare Co., Ltd., Seoul, South Korea) by at least one neurosurgeon, one radiologist and one neurosurgery physician.

The tumor MD of all planes (including coronal, sagittal and axial) was measured, and the tumor was categorized as a micro pituitary adenoma $(<10 \mathrm{~mm})$, large pituitary adenoma $(10 \leq \mathrm{MD}<0 \mathrm{~mm})$ or macro pituitary adenoma $(\geq 40 \mathrm{~mm})$, as described previously (21). The maximum coronal length (a) and the sagittal width (b) were measured on enhanced T1-weighted imaging, and the maximum height (c) was measured at the middle sella turcica (middle cavernous) in the coronal section. The tumor $\mathrm{V}$ was calculated as follows: $\mathrm{V}=\mathrm{a} \times \mathrm{b} \times \mathrm{c} \times \pi / 6$ (22).

Detection of hormone level by chemiluminescence. The levels of TSH, triiodothyronine (T3), thyroxine (T4), free triiodothyronine (FT3), free thyroxine (FT4), LH, FSH, PRL, ACTH, $\mathrm{GH}$, estradiol, testosterone and cortisol were measured. A volume of $10 \mathrm{ml}$ blood was collected from fasting outpatients (at 8:00 a.m.) and inpatients (at 7:00 a.m.), all of whom were in a resting state. Chemiluminescence was used to detect hormone levels using the ADVIA Centaur XP Immunoassay system (Siemens AG). The normal ranges of these hormones were: $\mathrm{GH},<10 \mu \mathrm{g} / \mathrm{l}$; ACTH, 4.7-48.8 pg/ml; T3, 0.92-2.79 $\mu \mathrm{g} / \mathrm{l}$; T4, 58.1-140.6 $\mu \mathrm{g} / \mathrm{l}$; FT3, 3.5-6.5 pmol/1; FT4, 11.5-22.7 pmol/1; TSH, 0.35-5.5 $\mu \mathrm{IU} / \mathrm{ml}$; PRL, 2.1-17.7 $\mu \mathrm{g} / 1$ (male), 2.8-29.2 $\mu \mathrm{g} / \mathrm{l}$ (female, not pregnant), 1.8-20.3 $\mu \mathrm{g} / 1$ (female, menopause) and 3.4-33.4 $\mu \mathrm{g} / \mathrm{l}$ (female, ovulatory phase); $\mathrm{FSH}$, 1.4-18.1 mIU/ml (male), 9.7-208 mIU/ml (female, pregnancy), 2.5-10.2 $\mathrm{mIU} / \mathrm{ml}$ (female, follicular phase), $1.5-9.1 \mathrm{mIU} / \mathrm{ml}$ (female, luteal phase) and 23-116 mIU/ml (female, menopause); and LH, 1.5-9.3 $\mathrm{mIU} / \mathrm{ml}$ (male), 1.9-12.5 mIU/ml (female, follicular phase), 8.7-76.3 $\mathrm{mIU} / \mathrm{ml}$ (female, ovulatory phase), 0.5-16.9 $\mathrm{mIU} / \mathrm{ml}$ (female, luteal phase) and 15.9-54 $\mathrm{mIU} / \mathrm{ml}$ (female, menopause). For suspected prolactinoma patients with significantly low PRL levels, the PRL level was retested with a dilution of 1:100 to exclude the Hook effect $(23,24)$. The PRL/MD $(\mu \mathrm{g} /(1 \times \mathrm{mm}))$ was the ratio of PRL $(\mu \mathrm{g})$ to MD (1 $\mathrm{x} \mathrm{mm})$. The PRL/V $\mu \mathrm{g} /\left(1 \mathrm{x} \mathrm{cm}^{3}\right)$ was the ratio of PRL $(\mu \mathrm{g})$ to $\mathrm{V}(1 \mathrm{x} \mathrm{cm})^{3}$.

Statistical analysis. SPSS 19.0 statistical software (IBM Corp., Armonk, NY, US) was used for statistical analysis. Normally distributed data are expressed as the mean \pm standard deviation. The values of PRL, PRL/MD and PRL/V that were not normally distributed are expressed as the median (range). Categorical data were compared using the $\chi^{2}$ test and quantitative data were compared using Student's t-test, analysis of variance followed by Tukey's test for post-hoc multiple comparisons and the rank sum test. The diagnostic sensitivity (SE), specificity (SP), positive predictive value (PPV) and negative predictive value (NPV), and the diagnostic accuracy of $\mathrm{PRL}, \mathrm{PRL} / \mathrm{MD}$ and $\mathrm{PRL} / \mathrm{V}$ were recorded. Receiver 
Table I. Clinical characteristics of all patients in the study.

\begin{tabular}{|c|c|c|c|}
\hline Characteristic & Group A $(n=30)$ & Group B $(n=88)$ & P-value \\
\hline Age, years ${ }^{\mathrm{a}}$ & $35.27 \pm 11.31$ & $47.61 \pm 12.65$ & $<0.001$ \\
\hline Gender (male:female), $n$ & $7: 23$ & $33: 55$ & 0.185 \\
\hline Hyperprolactinemia-related symptoms, n (\%) & $24(80.00)$ & $22(25.00)$ & $<0.001$ \\
\hline Amenorrhea & $17(56.67)$ & $14(15.91)$ & \\
\hline Lactation & $20(66.67)$ & $9(10.23)$ & \\
\hline Decreased sexual function & $0(0.00)$ & $7(7.95)$ & \\
\hline Fatigue & $0(0.00)$ & $4(4.55)$ & \\
\hline Adenoma mass effects, $\mathrm{n}(\%)$ & $19(63.33)$ & $81(92.05)$ & 0.001 \\
\hline Headache, dizziness & $14(46.67)$ & $51(57.95)$ & \\
\hline Visual impairment & $8(26.67)$ & $57(64.77)$ & \\
\hline \multicolumn{4}{|l|}{ PRL level, $\mu \mathrm{g} / \mathrm{l}$} \\
\hline Median (range) ${ }^{\mathrm{b}}$ & $114.71(31.74-238.16)$ & $44.42(18.03-220.59)$ & $<0.001$ \\
\hline $18-50$ & $4(13.33)$ & $55(62.50)$ & \\
\hline $50-100$ & $10(33.33)$ & $23(26.14)$ & \\
\hline $100-150$ & $4(13.33)$ & $8(9.09)$ & \\
\hline $150-250$ & $12(40.00)$ & $2(2.27)$ & \\
\hline \multicolumn{4}{|l|}{ Adenoma size $^{a}$} \\
\hline Maximum diameter, mm & $15.81 \pm 4.93$ & $29.00 \pm 10.97$ & $<0.001$ \\
\hline Volume, $\mathrm{cm}^{3}$ & $1.58 \pm 2.20$ & $8.21 \pm 8.53$ & $<0.001$ \\
\hline \multicolumn{4}{|l|}{ New indicators ${ }^{\mathrm{b}}$} \\
\hline PRL/MD, $\mu \mathrm{g} /(1 \times \mathrm{mm})$ & $7.77(1.73-17.01)$ & $1.70(0.45-11.59)$ & $<0.001$ \\
\hline $\mathrm{PRL} / \mathrm{V}, \mu \mathrm{g} /\left(1 \mathrm{x} \mathrm{cm}^{3}\right)$ & $107.55(5.29-360.99)$ & $9.15(0.68-117.50)$ & $<0.001$ \\
\hline
\end{tabular}

Data presented as amean \pm standard deviation and ${ }^{\mathrm{b}}$ mean (range).

operating characteristic (ROC) curves were drawn to identify the cut-off point [corresponding to the maximum Youden index (YI)]. The area under the curve (AUC) was compared using Student's t-test. $\mathrm{P}<0.05$ was considered to indicate a statistically significant difference.

\section{Results}

Characteristics of patients. The 118 pituitary adenoma cases with PRL between the upper limit of the normal range and $250 \mu \mathrm{g} / 1$ were included, including 30 cases in group A (prolactinoma group) and 88 cases in group B (other pituitary adenoma group). There was no significant difference in gender ratio between the two groups, with 7:23 (male:female) in group A and 33:55 in group B. However, there was a significant difference in age between group A (mean, 35.27 \pm 11.31 ; range, 19-64 years) and B (mean, 47.61 \pm 12.65 ; range, $20-74$ years) $(\mathrm{P}<0.05)$. Immunohistochemistry revealed that all cases in group A were prolactin-type (confirmed prolactinoma cases). In group B, there were 4 cases of GH-type adenoma, 4 cases of ACTH-type adenoma, 1 case of TSH-type adenoma, 29 cases of null cell adenoma, 33 cases of gonadotropic hormone (GnH)-type adenoma and 17 cases of plurihormonal-type adenoma (including 4 cases with tumors positive for ACTH $+\mathrm{FSH}+\mathrm{GH}+\mathrm{PRL}+\mathrm{TSH}, 1$ case positive for ACTH + PRL, 3 cases positive for $\mathrm{ACTH}+\mathrm{GH}+\mathrm{PRL}, 1$ case positive for

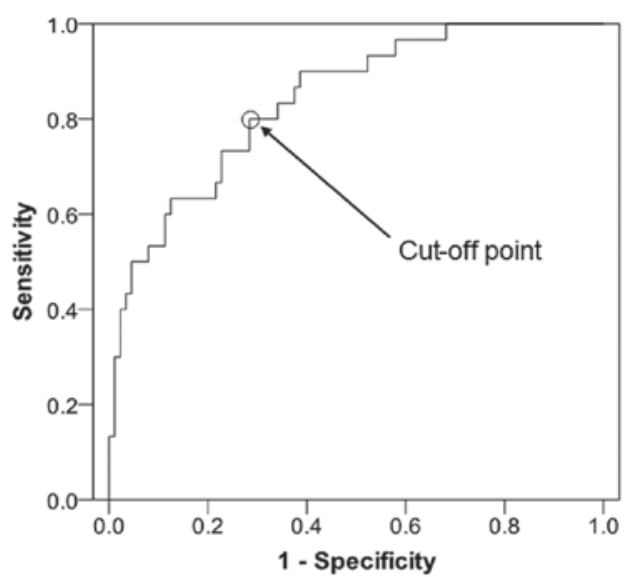

Figure 1. Receiver operating characteristic curve of PRL differentiation. PRL was used for differential diagnosis and immunohistochemistry results were used as the gold standard. Cut-off point, $55.65 \mu \mathrm{g} / \mathrm{l}$; AUC, 0.840; AUC standard error, 0.040; and 95\% confidence interval, 0.761-0.919. AUC, area under the curve; PRL, prolactin.

$\mathrm{ACTH}+\mathrm{GH}+\mathrm{LH}+\mathrm{PRL}+\mathrm{TSH}, 2$ cases positive for $\mathrm{ACTH}$ $+\mathrm{FSH}+\mathrm{GH}+\mathrm{LH}+\mathrm{PRL}+\mathrm{TSH}, 2$ cases positive for $\mathrm{FSH}+$ PRL, 1 case positive for PRL + TSH, 1 case positive for $\mathrm{GH}+$ TSH, 1 case positive for ACTH + GH + LH + PRL and 1 case positive for $\mathrm{ACTH}+\mathrm{FSH}+\mathrm{GH}+\mathrm{PRL})$. 
Table II. PRL differentiation of prolactinoma and other types of pituitary adenoma.

\begin{tabular}{|c|c|c|c|c|c|c|c|c|c|}
\hline $\mathrm{PLR}, \mu \mathrm{g} / 1$ & Diagnosis & Group A, n & Group B, n & Total & SE & SP & PPV & NPV & YI \\
\hline$>55.65$ & Prolactinoma & 24 & 4 & 28 & & & & & \\
\hline$\leq 55.65$ & Other pituitary adenomas & 6 & 84 & 90 & & & & & \\
\hline Total & & 30 & 88 & 118 & 0.800 & 0.716 & 0.857 & 0.933 & 0.516 \\
\hline
\end{tabular}

SE, sensitivity; SP, specificity; PPV, positive predictive value; NPV, negative predictive value; YI, Youden index; PRL, prolactin.

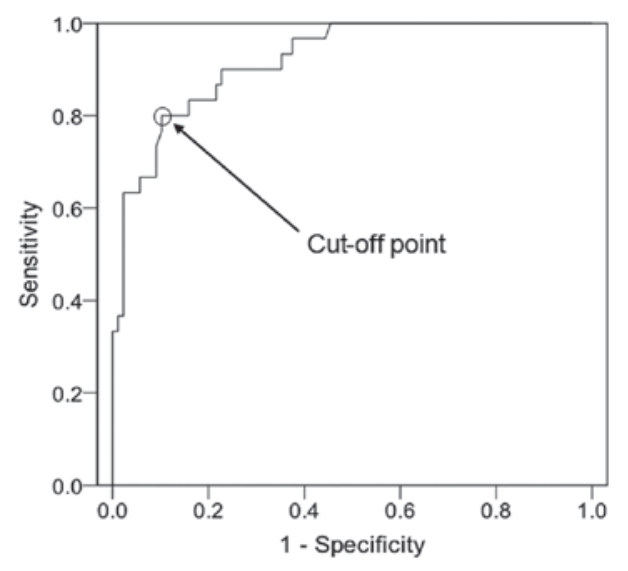

Figure 2. Receiver operating characteristic curve of PRL/MD differentiation. PRL/MD was used for differential diagnosis and immunohistochemistry results were used as gold standard. Cut-off point, $4.03 \mu \mathrm{g} /(1 \mathrm{x} \mathrm{mm})$; AUC, 0.920; AUC standard error, 0.027; and 95\% confidence interval, 0.868-0.972. AUC, area under the curve; PRL/MD, prolactin/adenoma maximum diameter.

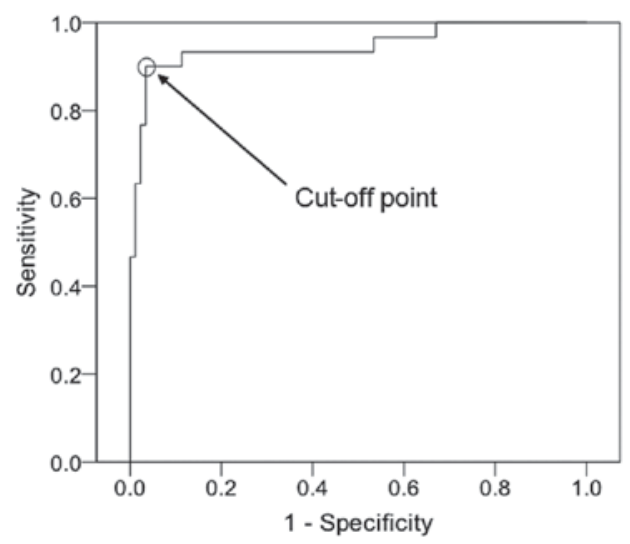

Figure 3. Receiver operating characteristic curve of PRL/V differentiation. PRL/V was used for differential diagnosis and immunohistochemistry results were used as gold standard. Cut-off point, $54.00 \mu \mathrm{g} /\left(1 \mathrm{x} \mathrm{cm}^{3}\right)$; AUC, 0.947; AUC standard error, 0.028; and 95\% confidence interval, 0.891-1.000. AUC, area under the curve; PRL/V, prolactin/adenoma volume.

There was a significant difference in the median PRL level between group A (114.71 $\mu \mathrm{g} / \mathrm{l}$; range, 31.74-238.16 $\mu \mathrm{g} / \mathrm{l})$ and group B (44.42 $\mu \mathrm{g} / \mathrm{l}$; range, 18.03-220.59 $\mu \mathrm{g} / \mathrm{l})(\mathrm{P}<0.05$; Table I). In group B, the median PRL level in null cell-, $\mathrm{GnH}$ - and plurihormonal-type adenomas was 45.6 (range, 18.03-131.12) $\mu \mathrm{g} / 1,35.3$ (range, 19.49-126.9) $\mu \mathrm{g} / 1$ and 51.17 (range, 21.97-220.59) $\mu \mathrm{g} / 1$, respectively. The PRL level in plurihormonal-type adenoma was significantly higher than that in $\mathrm{GnH}$-type adenoma $(\mathrm{P}<0.05$; data not shown). No significant difference was observed between null cell and plurihormonal-type adenomas or between null cell- and GnH-type adenomas ( $\mathrm{P}>0.05$; data not shown). The maximum diameter was $15.81 \pm 4.93 \mathrm{~mm}$ in group A and $29.00 \pm 10.97 \mathrm{~mm}$ in group $\mathrm{B}$, and the mean volume was $1.58 \pm 2.20 \mathrm{~cm}^{3}$ in group $\mathrm{A}$ and $8.21 \pm 8.53 \mathrm{~cm}^{3}$ in group $\mathrm{B}$, with a significant difference (Table I). The mean PRL/MD was $7.77 \mu \mathrm{g} /(1 \mathrm{x} \mathrm{mm})$ [range, $1.73-17.01 \mu \mathrm{g} /(1 \times \mathrm{mm})]$ in group A and $1.70 \mu \mathrm{g} /(1 \mathrm{x} \mathrm{mm})$ [range, $0.45-11.59 \mu \mathrm{g} /(1 \mathrm{x} \mathrm{mm})]$ in group $\mathrm{B}$, and the mean PRL/V was $107.55 \mu \mathrm{g} /\left(1 \mathrm{x} \mathrm{cm}^{3}\right)$ [range, 5.29-360.99 $\left.\mu \mathrm{g} /\left(1 \mathrm{x} \mathrm{cm}^{3}\right)\right]$ in group A and $9.15 \mu \mathrm{g} /\left(1 \mathrm{x} \mathrm{cm}^{3}\right)$ [range, $\left.0.68-117.50 \mu \mathrm{g} /\left(1 \mathrm{x} \mathrm{cm}^{3}\right)\right]$ in group $\mathrm{B}$, with a significant difference $(\mathrm{P}<0.001)$. These results indicated that there were significant differences in the PRL level, PRL/MD and PRL/V between the two groups, which may aid in achieving a differential diagnosis.

Differential diagnosis using symptoms. To determine the differential diagnostic ability of clinical symptoms, hyperprolactinemia symptoms and pituitary adenoma mass effects, these factors were compared between the two groups. There were 24 cases $(80.00 \%)$ in group A and 22 cases $(25.00 \%)$ in group B with hyperprolactinemia symptoms, including amenorrhea, lactation, decreased sexual function and fatigue, with significant differences $(\mathrm{P}<0.001)$. There were 19 cases $(63.33 \%)$ in group A and 81 cases $(92.05 \%)$ in group B with pituitary adenoma mass effects, including headache, dizziness and visual impairment, with significant differences $(\mathrm{P}=0.001)$ (Table I). The differential diagnostic ability of hyperprolactinemia symptoms, including amenorrhea, lactation, decreased sexual function and fatigue, was further analyzed by ROC. The results revealed that the diagnostic SE was 0.800 and the SP was 0.750 (data not shown). These results indicated that hyperprolactinemia symptoms alone could not effectively differentiate prolactinomas from other types of pituitary adenomas.

Differential diagnostic potential of PRL. To determine the differential diagnostic potential of PRL, the PRL level was compared between the two groups. The ROC curve of PRL is presented in Fig. 1 [cut-off point, $55.65 \mu \mathrm{g} / \mathrm{l}$; AUC, 0.840; AUC standard error, 0.040; and 95\% confidence interval (CI), 0.761-0.919]. The SE was 0.800 , the SP was 0.716 , the PPV was 0.857 , the NVP was 0.933 and the YI was 0.516 (Table II). These results indicate that PRL has a high differential diagnostic capacity, however, a number of patients may have been misdiagnosed based upon the low YI. 
Table III. PRL/MD differentiation of prolactinoma and other types of pituitary adenoma.

\begin{tabular}{|c|c|c|c|c|c|c|c|c|c|}
\hline $\mathrm{PLR} / \mathrm{MD}, \mu \mathrm{g} /(1 \times \mathrm{mm})$ & Diagnosis & Group A, n & Group B, n & Total & SE & SP & PPV & NPV & YI \\
\hline$>4.03$ & Prolactinoma & 24 & 9 & 33 & & & & & \\
\hline$\leq 4.03$ & Other pituitary adenomas & 6 & 79 & 85 & & & & & \\
\hline Total & & 30 & 88 & 118 & 0.800 & 0.898 & 0.727 & 0.929 & 0.698 \\
\hline
\end{tabular}

SE, sensitivity; SP, specificity; PPV, positive predictive value; NPV, negative predictive value; YI, Youden index; PRL/MD, prolactin/adenoma maximum diameter.

Table IV. PRL/V differentiation of prolactinoma and other types of pituitary adenoma.

\begin{tabular}{|c|c|c|c|c|c|c|c|c|c|}
\hline $\mathrm{PRL} / \mathrm{V}, \mu \mathrm{g} /\left(1 \times \mathrm{cm}^{3}\right)$ & Diagnosis & Group A, n & GroDup B, n & Total & SE & SP & PPV & NPV & YI \\
\hline$>54$ & Prolactinoma & 27 & 3 & 30 & & & & & \\
\hline$\leq 54$ & Other pituitary adenomas & 3 & 85 & 88 & & & & & \\
\hline Total & & 30 & 88 & 118 & 0.900 & 0.966 & 0.900 & 0.966 & 0.866 \\
\hline
\end{tabular}

SE, sensitivity; SP, specificity; PPV, positive predictive value; NPV, negative predictive value; YI, Youden index; PRL/V, prolactin/adenoma volume.

Table V. AUC comparison of receiver operating characteristic curve of PRL, PRL/MD and PRL/V.

\begin{tabular}{lcccc}
\hline Marker & AUC & Standard error & $95 \%$ CI & P-value \\
\hline PRL & 0.840 & 0.040 & $0.761-0.919$ & - \\
PRL/MD & 0.920 & 0.027 & $0.868-0.972$ & $0.097^{\text {a }}$ \\
PRL/V & 0.947 & 0.028 & $0.891-1.000$ & $0.028^{\text {a }}$ \\
\hline
\end{tabular}

${ }^{a}$ Compared with PRL. AUC, area under the curve; CI, confidence interval; PLR, prolactin; PLR/MD, PLR/adenoma maximum diameter; PLR/V, PLR/adenoma volume.

Differential diagnostic potential of PRL/MD. To determine the differential diagnostic potential of PRL/MD, PRL/MD was compared between the two groups. The ROC curve of PRL/MD is presented in Fig. 2 [cut-off point, $4.03 \mu \mathrm{g} /(1 \mathrm{x} \mathrm{mm}) ; \mathrm{AUC}$, 0.920; AUC standard error, 0.027; and 95\% CI, 0.868-0.972]. The SE was 0.898 , the SP was 0.727 , the PPV was 0.727 , the NVP was 0.929 and the YI was 0.698 (Table III). These results suggest that, due to its higher YI, PRL/MD may be more effective than PRL in differentiating prolactinomas from other types of pituitary adenomas.

Differential diagnostic potential of $P R L / V$. To determine the differential diagnostic potential of PRL/V, PRL/V was compared between the two groups. Group A was considered as a positive case group and group B was considered as a negative case group. The ROC curve of $\mathrm{PRL} / \mathrm{V}$ is presented in Fig. 3 [cut-off point, $54.00 \mu \mathrm{g} /\left(\mathrm{l} \mathrm{x} \mathrm{cm}^{3}\right)$; AUC, 0.947 ; AUC standard error, 0.028; and 95\% CI, 0.891-1.000]. The SE was 0.900 , the SP was 0.966 , the PPV was 0.900 , the NVP was 0.966 and the YI was 0.866 (Table IV). These findings indicate that PRL/V may have the greatest differential diagnostic potential among these three indicators, due to the fact that its YI is the greatest.

Comparison of the differential diagnostic potential of PRL, $P R L / M D$ and $P R L / V$. To compare the differential diagnostic potential of PRL, PRL/MD and PRL/V, an ROC curve and a Student's t-test were performed. The ROC curves of PRL, PRL/MD and PRL/V are presented in Figs. 1-3, and the AUC comparison is presented in Table V. PRL/MD tended to be more diagnostically accurate than PRL, but without a significant difference $(\mathrm{P}=0.097)$. $\mathrm{PRL} / \mathrm{V}$ was of higher diagnostic accuracy compared with $\mathrm{PRL}$, with significance $(\mathrm{P}=0.028)$. Therefore, PRL/V had a greater potential to differentially diagnose when compared with the PRL level. Furthermore, PRL/MD had a greater potential to differentially diagnose when compared with the PRL level, but without statistical significance.

\section{Discussion}

The present study is the first to propose the use of PRL/MD and PRL/V as diagnostic tools to distinguish prolactinoma from other types of pituitary adenomas. The optimal PRL differentiation level was $55.65 \mu \mathrm{g} / 1$ with a YI of 0.516 , the optimal PDL/MD differentiation ratio was $4.03 \mu \mathrm{g} /(1 \mathrm{x} \mathrm{mm})$ with a YI of 0.698 , and the optimal PRL/V differentiation ratio was $54.00 \mu \mathrm{g} /\left(1 \mathrm{x} \mathrm{cm}^{3}\right)$ with a YI of 0.866 . PRL/MD appeared to have a greater diagnostic accuracy than PRL, but with no statistical significance $(\mathrm{P}=0.097)$, while the greater diagnostic accuracy of the PRL/V compared with that of PRL was statistically significant $(\mathrm{P}=0.028)$. Therefore, for pituitary adenoma patients with PRL between the upper limit of the normal range and $250 \mu \mathrm{g} / \mathrm{l}, \mathrm{PRL} / \mathrm{V}$ may be a more efficient tool for differential diagnosis than PRL. 
Patients with hyperprolactinemia symptoms were often believed to have prolactinoma with a high rate of misdiagnosis (25). In the present study, there were 24 cases $(80.00 \%)$ in group A and 22 cases $(25.00 \%)$ in group B with hyperprolactinemia symptoms, and 19 patients $(63.33 \%)$ in group A and 81 cases $(92.05 \%)$ in group B with pituitary adenoma mass effects. Although there were significant differences in clinical symptoms between groups A and B, the use of hyperprolactinemia symptoms in diagnosis led to a high rate of misdiagnosis (SE, 0.800; SP, 0.750).

The PRL level is frequently used for differential diagnosis. In cases where pituitary adenoma was present along with hyperprolactinemia (15), prolactinoma was clinically considered. PRL $>500 \mu \mathrm{g} / 1$ was considered to reflect the presence of large prolactinoma (26), and pituitary adenoma with PRL $>250 \mu \mathrm{g} / 1$ was considered to indicate likely prolactinoma (27). However, in clinical practice, the optimal PRL level for the differential diagnosis of prolactinoma and other types of pituitary adenoma is far from $250 \mu \mathrm{g} / 1$. Kawaguchi et al (28) reported that the optimal PRL level for the differential diagnosis of prolactinoma and non-functioning adenomas was $38.6 \mu \mathrm{g} / 1$, which is substantially lower than 100-200 ng/ml. Karavitak et al (6) demonstrated that the PRL level of non-functional pituitary adenomas did not exceed 2,000 mIU/1 (1 $\mu \mathrm{g} / \mathrm{l}=21.2 \mathrm{mIU} / \mathrm{l})$, and 2,000 mIU/l was considered as the upper PRL limit of non-functional pituitary adenomas. However, Hong et al (14) revealed that $5 / 35$ patients with non-functional pituitary adenoma exhibited hyperprolactinemia and a PRL level $>100 \mu \mathrm{g} / \mathrm{l}$. A total of $1.3-11.8 \%$ non-functional pituitary adenoma patients exhibited a PRL level $>100 \mu \mathrm{g} / 1(6,14,29)$. The Europe Endocrine Society recommended that pituitary adenomas with a PRL level $>250 \mu \mathrm{g} / \mathrm{l}$ should be diagnosed as prolactinoma (15). The PRL level of patients with secondary hyperprolactinemia caused by pituitary stalk compression was likely between $25-200 \mu \mathrm{g} / 1(11,30)$. Therefore, the gray area (the upper limit of the normal range to $250 \mu \mathrm{g} / \mathrm{l}$ ) may easily lead to a misdiagnosis. In the present study, the optimal PRL level for differential diagnosis was $55.65 \mu \mathrm{g} / 1$, with an SE of 0.800 and an SP of 0.716. Therefore, a higher diagnostic accuracy is required.

The differentiation between prolactinoma and other types of pituitary adenomas is essential for making decisions regarding treatment. Dopamine agonists, which lead to tumor cell apoptosis and secondary necrosis, are the first line of treatment for prolactinomas $(15,31,32)$. However, bromocriptine should be administered for $\geq 3$ months for other types of pituitary adenomas in order to rule out prolactinoma (6). This is not only time-consuming, but may also aggravate adenoma fibrosis (33) and increase surgical risks. Additionally, unnecessary surgery for prolactinoma may increase the financial burden on the patient. In addition to treating prolactinoma, dopamine agonists may also reduce PRL levels in other types of pituitary adenomas with hyperprolactinemia and may relieve hyperprolactinemia symptoms. However, the effects of these drugs on the volume of adenoma remain unclear $(9,15)$. Patients exhibiting $\mathrm{GH}$, TSH or ACTH above the upper normal limits were excluded from the present study.

There are some limitations to the present study. Firstly, for a small portion of the patients, the PRL level, PRL/MD and PRL/V were not able to accurately differentiate between disease types. Secondly, the sample size was small and data was collected from a single center. Therefore, multi-center and prospective clinical studies are required to further elucidate the role of PRL/MD and PRL/V in the differential diagnosis of adenoma.

In conclusion, serum PRL, PRL/MD and PRL/V were useful in the differential diagnosis of pituitary adenomas. For pituitary adenoma patients with a PRL level between the upper limit of the normal range and $250 \mu \mathrm{g} / 1$, imaging combined with plasma hormone level detection may improve the accuracy of the differential diagnosis. PRL/V may be more accurate for the differential diagnosis than PRL, and the optimal PRL/V ratio in the differentiation of prolactinomas from other types of hyperprolactinemia-causing pituitary adenomas in this study was $54.00 \mu \mathrm{g} /\left(1 \mathrm{x} \mathrm{cm}^{3}\right)$.

\section{Acknowledgements}

The authors would like to thank Dr Qun Zhong (Department of Radiology, Fuzhou General Hospital, Fujian, China) for aiding in the preparation of the original manuscript. The present study was supported by Nanjing Military Region Fuzhou General Hospital Innovation (grant no. 2014CXTD07) and Nanjing Military Region Fuzhou General Hospital Young Talent (grant no. 2014Q32).

\section{References}

1. Wass JA and Karavitaki N: Nonfunctioning pituitary adenomas: The oxford experience. Nat Rev Endocrinol 5: 519-522, 2009.

2. Capozzi A, Scambia G, Pontecorvi A and Lello S: Hyperprolactinemia: Pathophysiology and therapeutic approach. Gynecol Endocrinol 31: 506-510, 2015.

3. Sakurai T, Seo H, Yamamoto N, Nagaya T, Nakane T, Kuwayama A, Kageyama N and Matsui N: Detection of mRNA of prolactin and ACTH in clinically nonfunctioning pituitary adenomas. J Neurosurg 69: 653-659, 1988.

4. Beentjes JA,Tjeerdsma G, Sluiter WJ and DullaartRP: Divergence between growth hormone responses to insulin-induced hypoglycaemia and growth hormone-releasing hormone in patients with non-functioning pituitary macroadenomas and hyperprolactinaemia. Clin Endocrinol (Oxf) 45: 391-398, 1996.

5. Fonseca AL, Chimelli L, Santos MJ, Santos AA and Violante AH: Influence of hyperprolactinemia and tumoral size in the postoperative pituitary function in clinically nonfunctioning pituitary macroadenomas. Arq Neuropsiquiatr 60: 590-602, 2002 (In Portuguese).

6. Karavitaki N, Thanabalasingham G, Shore HC, Trifanescu R, Ansorge O, Meston N, Turner HE and Wass JA: Do the limits of serum prolactin in disconnection hyperprolactinaemia need re-definition? A study of 226 patients with histologically verified non-functioning pituitary macroadenoma. Clin Endocrinol (Oxf) 65: 524-529, 2006.

7. Cury ML, Fernandes JC, Machado HR, Elias LL, Moreira AC and Castro $\mathrm{Md}$ : Non-functioning pituitary adenomas: Clinical feature, laboratorial and imaging assessment, therapeutic management and outcome. Arq Bras Endocrinol Metabol 53: 31-39, 2009.

8. Berkmann S, Fandino J, Muller B, Remonda L and Landolt H: Intraoperative MRI and endocrinological outcome of transsphenoidal surgery for non-functioning pituitary adenoma. Acta Neurochir (Wien) 154: 639-647, 2012.

9. Colao A, Di Somma C, Pivonello R, Faggiano A, Lombardi G and Savastano S: Medical therapy for clinically non-functioning pituitary adenomas. Endocr Relat Cancer 15: 905-915, 2008.

10. Zhao W, Ye H, Li Y, Zhou L, Lu B, Zhang S, Wen J, Li S, Yang Y and Hu R: Thyrotropin-secreting pituitary adenomas: Diagnosis and management of patients from one Chinese center. Wien Klin Wochenschr 124: 678-684, 2012. 
11. Behan LA, O'sullivan EP, Glynn N, Woods C, Crowley RK, Tun TK, Smith D, Thompson CJ and Agha A: Serum prolactin concentration at presentation of non-functioning pituitary macroadenomas. J Endocrinol Invest 36: 508-514, 2013.

12. Shimon I, Jallad RS, Fleseriu M, Yedinak CG, Greenman Y and Bronstein MD: Giant GH-secreting pituitary adenomas: Management of rare and aggressive pituitary tumors. Eur J Endocrinol 172: 707-713,2015.

13. Ferrante E, Ferraroni M, Castrignanò T, Menicatti L, Anagni M, Reimondo G, Del Monte P, Bernasconi D, Loli P, Faustini-Fustini M, et al: Non-functioning pituitary adenoma database: A useful resource to improve the clinical management of pituitary tumors. Eur J Endocrinol 155: 823-829, 2006.

14. Hong JW, Lee MK, Kim SH and Lee EJ: Discrimination of prolactinoma from hyperprolactinemic non-functioning adenoma. Endocrine 37: 140-147, 2010.

15. Melmed S, Casanueva FF, Hoffman AR, Kleinberg DL, Montori VM, Schlechte JA and Wass JA; EndocrineSociety: Diagnosis and treatment of hyperprolactinemia: An Endocrine Society clinical practice guideline. J Clin Endocrinol Metab 96 273-288, 2011

16. Zhu M, Zhang $\mathrm{Y}$ and Peng H: Comparative Analysis and Clinical Application of Serum PRL and MRI Scan on Pituitary Prolactinoma. J Radioimmunol, 2013.

17. Smith MV and Laws ER Jr: Magnetic resonance imaging measurements of pituitary stalk compression and deviation in patients with nonprolactin-secreting intrasellar and parasellar tumors: Lack of correlation with serum prolactin levels. Neurosurgery 34: 834-839, 1994

18. Delellis RA: Pathology and genetics of tumours of endocrine organs. IARC Press, 2004.

19. Trouillas J, Roy P, Sturm N, Dantony E, Cortet-Rudelli C, Viennet G, Bonneville JF, Assaker R, Auger C, Brue T, et al: A new prognostic clinicopathological classification of pituitary adenomas: A multicentric case-control study of 410 patients with 8 years post-operative follow-up. Acta Neuropathol 126: 123-135, 2013.

20. Jan M, Dufour H, Brue T and Jaquet P: Prolactinoma surgery. Ann Endocrinol (Paris) 68, 118-119, 2007.

21. Gruppetta $M$ and Vassallo J: Epidemiology and radiological geometric assessment of pituitary macroadenomas: Population-based study. Clin Endocrinol (Oxf) 85: 223-231, 2016.
22. Osamura RY, Kajiya H, Takei M, Egashira N, Tobita M, Takekoshi S and Teramoto A: Pathology of the human pituitary adenomas. Histochem Cell Biol 130: 495-507, 2008.

23. Barkan AL and Chandler WF: Giant pituitary prolactinoma with falsely low serum prolactin: The pitfall of the 'high-dose hook effect': Case report. Neurosurgery 42: 913-916, 1998.

24. Petakov MS, Damjanović SS, Nikolić-Durović MM, Dragojlović ZL, Obradović S, Gligorović MS, Simić MZ and Popović VP: Pituitary adenomas secreting large amounts of prolactin may give false low values in immunoradiometric assays. The hook effect. J Endocrinol Invest 21: 184-188, 1998.

25. Romijn JA: Hyperprolactinemia and prolactinoma. Handb Clin Neurol 124: 185-195, 2014.

26. Vilar L, Freitas MC, Naves LA, Casulari LA, Azevedo M, Montenegro R Jr, Barros AI, Faria M, Nascimento GC, Lima JG, et al: Diagnosis and management of hyperprolactinemia: Results of a Brazilian multicenter study with 1234 patients. J Endocrinol Invest 31: 436-444, 2008.

27. Paepegaey AC, Veron L, Wimmer MC and Christin-Maitre S: Misleading diagnosis of hyperprolactinemia in women. Gynecol Obstet Fertil 44: 181-186, 2016 (In French).

28. Kawaguchi T, Ogawa Y and Tominaga T: Diagnostic pitfalls of hyperprolactinemia: The importance of sequential pituitary imaging. BMC Res Notes 7: 555, 2014.

29. Ross RJ, Grossman A, Bouloux P, Rees LH, Doniach I and Besser GM: The relationship between serum prolactin and immunocytochemical staining for prolactin in patients with pituitary macroadenomas. Clin Endocrinol (Oxf) 23: 227-235, 1985.

30. Arafah BM, Nek1 KE, Gold RS and Selman WR: Dynamics of prolactin secretion in patients with hypopituitarism and pituitary macroadenomas. J Clin Endocrinol Metab 80: 3507-3512, 1995.

31. Pala NA, Laway BA, Misgar RA and Dar RA: Metabolic abnormalities in patients with prolactinoma: Response to treatment with cabergoline. Diabetol Metab Syndr 7: 99, 2015.

32. Wong A, Eloy JA, Couldwell WT and Liu JK: Update on prolactinomas. Part 2: Treatment and management strategies. J Clin Neurosci 22: 1568-1574, 2015.

33. Menucci M, Quinones-Hinojosa A, Burger P and Salvatori R: Effect of dopaminergic drug treatment on surgical findings in prolactinomas. Pituitary 14: 68-74, 2011. 